\title{
Closing Racial-Ethnic Gaps in Poverty How Government Programs Compare
}

\author{
Marybeth J. Mattingly and Jessica A. Carson
}

A lthough the role of government programs in alleviating poverty is widely studied, far less attention is paid to how these programs may differentially impact people with different racial-ethnic identities. Given that poverty rates among non-Hispanic whites are significantly lower than among other groups, programs with disparate effects by race can either widen or decrease racial-ethnic gaps in the poverty rate. The figure shows that the Supplemental Nutrition Assistance Program (SNAP) plays an important poverty amelioration role for blacks and Hispanics: without it, the gap between these groups and non-Hispanic whites would widen. The federal Earned Income Tax Credit (EITC), in turn, plays a particularly important role for Hispanic populations; without the EITC, Hispanic poverty rates would rise from 21.9 percent to 24.1 percent, and the gap between white and Hispanic rates would increase by 3.3 percentage points. Finally, Social Security is especially important in maintaining low poverty rates among whites, but without it, the poverty gap between white and non-white populations would be much smaller. Policymakers who want to not only advance low income populations, but also promote racial-ethnic equity, can consider these programs' roles in reducing poverty and racial-ethnic poverty gaps.

\section{POVERTY RATES AND POVERTY GAPS BY RACE-ETHNICITY}

-White, non-Hispanic $\square$ Black, non-Hispanic $\quad$ Hispanic $\square$ Asian, non-Hispanic

30

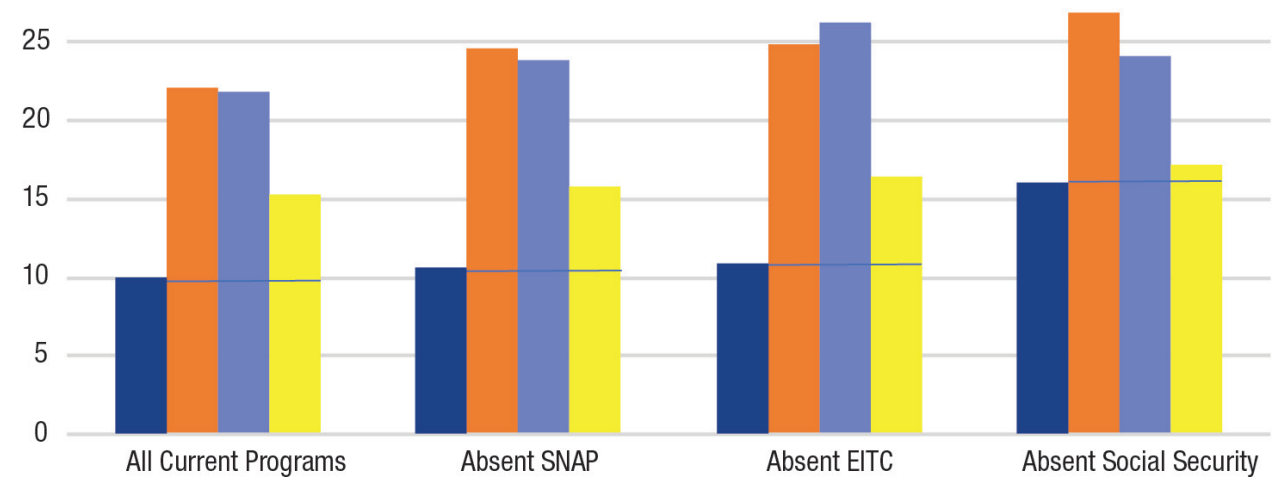

Note: "All current programs" is equivalent to the SPM poverty rate for each racial-ethnic group. The blue line is set at the level of white, non-Hispanic poverty rates, so that the distance between the blue line and the top of each column is the size of the poverty gap under each scenario. "EITC" refers to the federal credit only, and is based on a tax model that assumes takeup by all eligible filers. Source: CPS ASEC 2016-2018.

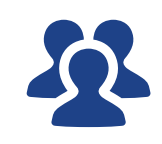

Using the Supplemental Poverty Measure, the poverty rate for blacks and Hispanics is more than twice that of non-Hispanic whites.

See related publications at carsey.unh.edu

- The Poverty-Reducing Effect of Five Key Government Programs in Rural and Urban America (April 2019)

- Gains in Reducing Child Poverty, but Racial-Ethnic Disparities Persist (April 2017)

This analysis was made possible by funding from the Annie E. Casey Foundation. 